\title{
O HUMOR NAS REDES SOCIAIS: A SÁTIRA SOBRE A POLÍTICA EM A LUTA
}

\author{
DANTIELLI ASSUMPÇÃO GARCIA ${ }^{1}$, \\ GIOVANNA BENEDETTO FLORES ${ }^{2}$
}

\author{
Universidade Estadual do Oeste do Paraná \\ R. Universitária, 1619 - Universitário - 85819-110 - Cascavel-PR - Brasil \\ Universidade do Sul de Santa Catarina \\ Avenida Pedra Branca, 25 - Cidade Universitária Pedra Branca - 88137-272 - \\ Palhoça-SC - Brasil \\ dantielligarcia@gmail.com, gbflores@gmail.com
}

\begin{abstract}
Resumo. Neste trabalho, da perspectiva teórica da Análise de Discurso pecheutiana, pretendemos analisar como a política e o humor entram em funcionamento em algumas postagens compartilhadas pela página A Luta no Facebook. Pelo efeito humorístico, a página vai formulando um dizer sobre a situação política brasileira após o impeachement da presidenta Dilma Rousseff e a chegada ao poder do vice-presidente Michel Temer. Denunciando a (i)legitimidade do governo, a página A Luta produz um riso que não reconcilia, mas se rebela diante das condições atuais brasileiras.

Palavras-chave: A Luta; humor; Dilma Rousseff; Michel Temer; Análise de Discurso.
\end{abstract}

\begin{abstract}
In this work, from the theoretical perspective of Pêcheux's Discourse Analysis, we study how politics and humor come into operation in some posts shared by A Luta webpage on Facebook. Through the humorous effect, the webpage designs a saying about the Brazilian political situation after the impeachement of president Dilma Rousseff, and vice president Michel Temer's arrival to power. Denouncing the (il)legitimacy of the government, A Luta webpage produces a laughter that does not reconcile, but rebels against the current Brazilian conditions.
\end{abstract}

Keywords: A Luta webpage; humor; Dilma Rousseff; Michel Temer; Discourse Analysis.

\footnotetext{
${ }^{1}$ Doutora em Estudos Linguísticos pela Universidade Estadual Paulista Júlio de Mesquita Filho. Docente no curso de Graduação em Letras da Universidade Estadual do Oeste do Paraná.

${ }^{2}$ Doutora em Linguística pela Universidade Estadual de Campinas. É professora titular do Programa de Pós-Graduação em Ciências da Linguagem e do curso de Jornalismo da Universidade do Sul de Santa Catarina.
} 


\section{Dizeres iniciais: A Luta e Temer}

A proposta deste trabalho é pensar a relação entre política e humor em postagens no Facebook da página A Luta. A rede social no Brasil, em especial o Facebook, tem sido lugar de grande manifestação política, principalmente, depois do impeachment da presidenta Dilma Rousseff e a entrada do governo Michel Temer. O que temos observado é que as críticas ao atual governo, nas redes sociais, têm sido elaboradas por meio da sátira e do humor. A partir da teoria francesa da Análise de Discurso, criada por Pêcheux na França, na década de 1960, e difundida no Brasil, por Eni Orlandi e demais pesquisadores, nos propomos a analisar o funcionamento do discurso nas redes sociais, sua formulação, constituição e circulação, tendo como corpus a página A Luta, a fim de compreender como os sentidos são produzidos pelas postagens que ali fazem falar o cenário político brasileiro. Entendemos que a linguagem é transformadora e marcada pelo processo social e histórico, no qual o jogo da constituição da linguagem se dá por meio dos processos histórico-sociais, mostrando que a palavra é uma prática social determinada por certos efeitos políticos-ideológicos do texto. Se o discurso é efeito de sentido entre locutores, é através do funcionamento da linguagem que podemos observar discursivamente a relação dos sujeitos e dos sentidos afetados pela língua e pela história. Como nos ensina Pêcheux (1975), os sujeitos são constituídos na/pela linguagem, marcados histórica e ideologicamente. Portanto, nos interessa analisar discursivamente os efeitos políticos-ideológicos de postagens em circulação na rede social Facebook e como são (re)significadas na forma de humor.

Nosso trabalho divide-se em dois momentos. Inicialmente, faremos uma discussão sobre o humor. Para tanto, nos amparamos, para teorizarmos o modo como compreendemos o humor, em estudos psicanalíticos (FREUD [1927] 1980; MORAIS, 2008) e filosóficos (LIPOVETSKY, 1989; BERGSON [1899] 2004). Em seguida, analisaremos as postagens compartilhadas na página A Luta que dizem sobre a situação política brasileira. $\mathrm{Na}$ análise dessas postagens, retomamos as condições de produção que permitem a emergência de dizeres sobre o atual presidente do Brasil: Michel Temer.

\section{O humor: o prazer pelo riso}

O humor não é resignado, mas rebelde. Significa não apenas o triunfo do ego, mas também o do princípio do prazer, que pode aqui afirmar-se contra a crueldade das circunstâncias reais. (FREUD, [1927] 1980, v. XXI, p. 190)

Após a destituição, por meio de um golpe político-jurídico-midiático, de uma presidenta legitimamente reeleita, a ascensão ao poder de um vice-presidente com uma plataforma governamental que atende aos interesses do capital e violenta, com propostas de 12 horas de trabalho diário, de 49 anos de contribuição para a aposentadoria, o brasileiro que foi ou não às ruas pedir o impeachment da presidenta Dilma Rousseff. Diante desse cenário de um governo (i)legítimo, começam a circular na rede social Facebook diversas postagens que, usando do humor, fazem resistência e dizem sobre as 
"crueldades" das circunstâncias políticas/governamentais brasileiras. Uma página do Facebook que marcou/marca essa luta pelos sentidos e dizeres é A Luta:

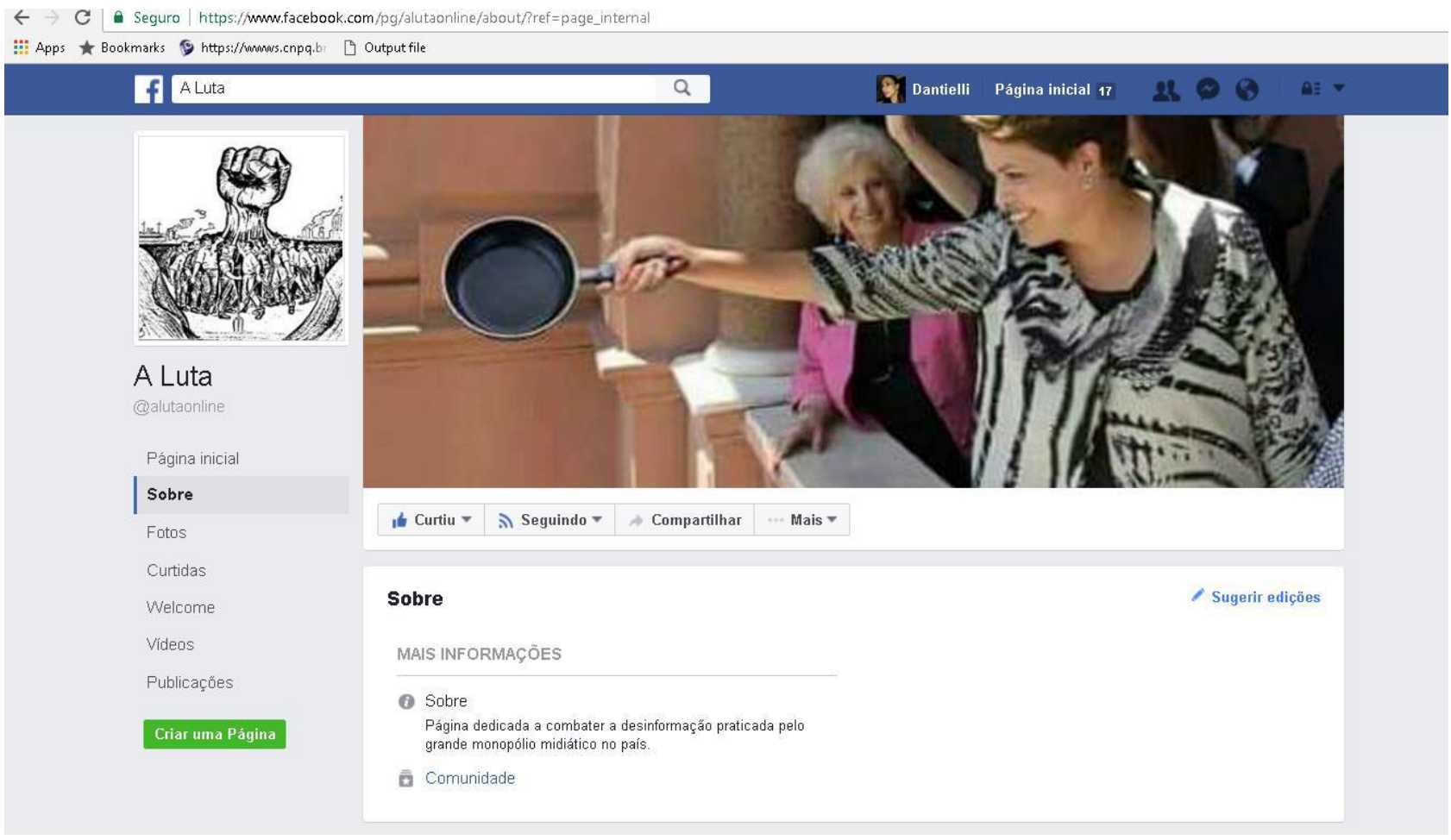

Figura 1: A Luta. Fonte: https://www.facebook.com/pg/alutaonline/about/?ref=page_internal.

Com a proposta de informar os sujeitos-navegadores, a página A Luta constitui-se por meio de postagens que, fazendo uso do efeito de humor, discorrem sobre a política brasileira. A foto de capa da página já indicia esse efeito. Com a imagem da presidenta Dilma Rousseff segurando uma panela, rememoram-se os panelaços que ocorreram no Brasil no período do processo do impeachment. As batidas das panelas tentavam silenciar os inúmeros pronunciamentos feitos pela presidenta em rede nacional. Ao oferecer a panela, nesse jogo jocoso e humorístico, efeitos de luta são instaurados. Mesmo ocorrendo os panelaços, essa tentativa de que a voz de quem não é criminoso seja silenciada, a resistência se dará. Uma resistência que fará uso da linguagem, do humor para dizer do que não se deve dizer, do que não se quer ouvir. Conforme Lendro-Ferreira (2015, p.159), enunciados como brincadeiras e chistes, "apontam para a resistência, na margem entre a dominação que se pretende fazer dela e a que ela - a língua(gem) estabelece." Ainda segundo a autora:

o sujeito resiste à dominação, resiste ao enquadramento, à manipulação, nem sempre de forma consciente e nem sempre de forma exitosa, mas o faz sem cessar. Ao resistir, o sujeito deixa materializados na linguagem suas falhas, suas contradições e seus enfrentamentos. (LEANDRO-FERREIRA, 2015, p.165)

Como afirma Morais (s.d.), o humor é político, pois é "uma forma de desconstrução, pelas beiradas, do poder instituído, para que o sujeito reafirme o seu desejo 
e restaure o seu direito de existir numa comunidade social". Reafirmando seu direito de existir, os sujeitos-navegadores, ao postarem suas opiniões e seus posicionamentos políticos no Facebook, intentam desestabilizar os sentidos, instaurados, principalmente, pela mídia, à política brasileira e ao presidente Michel Temer. Para isso, fazem uso do humor enquanto afirmação de um desejo diante da adversidade política (violenta, dicotômica) instalada após o processo de impeachment.

Gilles Lipovetsky, em A era do vazio - Ensaio sobre o individualismo contemporâneo (1989), afirma que vivemos em uma "sociedade humorística", na qual um código e um estilo humorístico dominam desde a publicidade até a política, da moda às produções acadêmicas, da arte aos meios de comunicação, na qual, além disso, as relações interpessoais são caracterizadas por um modo irreverente, cuja orientação é a que a vida deva ser vivida de forma cool [legal], ou ligth [leve] ou fun [divertida]:

[...] só a sociedade pós-moderna pode dizer-se humorística, só ela se institui globalmente sob a égide de um processo tendente a dissolver a oposição, até então estrita, do sério e do não-sério, na esteira das outras grandes divisões, a do cômico e do cerimonial esbate-se em benefício de um clima largamente humorístico. (LIPOVETSKY, 1989, p. 129).

A sociedade pós-moderna, porém, não detém o monopólio do cômico. Em todas as sociedades, desde as mais selvagens, o riso e os divertimentos ocuparam seus lugares. De acordo com Lipovetsky (1989), podemos dividir o cômico em três grandes fases. Na primeira, durante a Idade Média/Renascimento, o riso surge relacionado à profanação dos elementos sagrados, à violação das regras oficiais, sendo um riso mais carnavalesco. $\mathrm{Na}$ Idade Clássica, a segunda fase do cômico, o riso disciplina-se, isto é, há a perda da coletividade e do ritual que circundavam o riso, tornando-o uma experiência individualizada e sem a quebra das hierarquias para provocar o humor. Já na terceira fase, na qual vivemos hoje, o lúdico do riso é o elemento principal, sendo o humor permeado pela moda, pela publicidade, aparelhos eletrônicos, quadrinhos e desenhos animados e esvaziado de uma negatividade típica da zombaria, adotando, assim, uma postura eufórica, bem humorada e feliz: "O humor de massa já não repousa num fundo de amargura ou aborrecimento: longe de mascarar um pessimismo ou de ser a 'delicadeza do desespero', o humor contemporâneo quer-se sem espessura e descreve um universo radioso" (LIPOVETSKY, 1989, p. 131).

Como já apontava Freud ([1927] 1980), a essência do humor é poupar afetos. De um encontro faltoso com o real, o humorista escamoteia o mal-estar e cria um dito espirituoso, sendo uma forma de lidar com a dor e o sofrimento e ainda tirar prazer disto. O humor "pode ser um último véu a cobrir e descobrir o horror" (MORAIS, 2008, p. 116117) diante da pulsão de morte que habita o sujeito. O humor torna o sujeito capaz de rir de si mesmo e obter prazer apesar dos afetos dolorosos:

como os chistes e o cômico, o humor tem algo de liberador a seu respeito, mas possui também qualquer coisa de grandeza e elevação que faltam às outras duas maneiras de obter prazer da atividade intelectual. Essa grandeza reside claramente no triunfo do narcisismo, na afirmação vitoriosa da invulnerabilidade do ego. O ego se recusa a ser afligido pelas provocações da realidade a permitir que seja compelido a sofrer. Insiste em que não pode ser afetado pelos traumas do mundo externo; 
demonstra, na verdade, que esses traumas para ele não passam de ocasiões para obter prazer. (FREUD, [1927] 1980, p. 190)

São nos efeitos de sentidos humorísticos que se revelam as contradições, as falhas, as imperfeições da sociedade. O humor é transgressor, sendo uma forma de lidar com as dores do existir sem perder a graça. Nas postagens, a graça, o riso, emergem ao se discorrer sobre as ações governamentais do presidente Michel Temer. Como sua ascensão ao poder se dá pela via do golpe, embora seja transvestido pela mídia como um impeachment legal, já que não foi comprovado que a Presidenta tinha cometido crime, os sujeitos fazem uso do humor para criticarem a legalidade do processo e para marcarem uma não aceitação ao presidente que chega ao poder. Brincando com a linguagem e com o riso, os sujeitos no espaço da rede fazem reverberar o grito de "Rala Temer" e o pedido de novas eleições começam a circular.

Bergson, em O riso - Ensaio sobre a significação do cômico ([1899] 2004) ${ }^{3}$, aponta três aspectos ligados ao riso: não há comicidade fora do que é propriamente humano; há alguma insensibilidade que acompanha o riso; e o riso sempre exige uma participação de quem dele compartilhe, uma vez que "o nosso riso é sempre o riso de um grupo" (BERGSON, [1899] 2004, p. 8). Conforme o autor, o riso decorre das relações sociais, sendo assim:

para compreender o riso, temos de o repor no seu meio natural, que é a sociedade, temos sobretudo de determinar a sua utilidade de função, a sua função social. Eis, digamo-lo desde já, a ideia de diretriz de todas as nossas indagações. O riso deve dar a resposta a certas exigências da vida em comum. O riso deve ter uma significação social. (BERGSON, [1899] 2004, p. 6)

A afirmação de que o riso "deve ter uma função social" leva-nos, considerando as postagens que analisaremos enquanto materialidades discursivas do humor, a observar as condições de produção de tal discurso. Enquanto o cômico tende à universalidade, o humor marca o traço do particular, "é preciso ser da paróquia para se entender uma piada ou um dito espirituoso" (MORAIS, 2008, p. 117-118). Portanto, é preciso saber sobre o processo de impeachment brasileiro, acerca da (i)legitimidade do presidente para que o riso se instaure e marque a "crueldade" das circunstâncias atuais brasileiras.

Como condições de produção ${ }^{4}$ desses dizeres, temos o ano de 2016. A situação política no Brasil nesse ano sustentou-se no embate entre dois discursos: um da legalidade do mandato da Presidenta Dilma Rousseff e o outro da legalidade do processo de impeachment. Essa emergência de dizeres sobre Michel Temer surge a partir do processo (midiatizado) de impeachment em que o vice-presidente assume o poder e passa a

\footnotetext{
${ }^{3}$ Vale salientar que os temas riso e cômico estavam sendo muito trabalhados na segunda metade do século XIX e vários autores antes e depois de Freud escreveram sobre eles. No campo da filosofia, o livro $O$ riso (obra de grande bojo teórico), de Henri Bergson, publicado originalmente em 1899 na Révue de Paris, é um desses exemplos.

4 "Passei os quatro primeiros anos de governo como vice decorativo. A Senhora sabe disso. Perdi todo protagonismo político que tivera no passado e que poderia ter sido usado pelo governo. Só era chamado para resolver as votações do PMDB e as crises políticas". Trecho da carta enviada à Presidenta por Michel Temer. Disponível em http:/g1.globo.com/politica/noticia/2015/12/leia-integra-da-carta-enviada-pelo-vice-micheltemer-dilma.html.
} 
comandar o cenário político brasileiro, não mais como "decorativo" (lembremos a carta enviada por Temer à Presidenta Dilma Rousseff em que fala sobre sentir um vice "decorativo"), mas sim como detentor das decisões finais sobre o Brasil. Como apontam Medeiros e Sousa (s.d.),

tal situação de litígio recupera sentidos de aceitação do fascismo, do nazismo, da violência do Estado e da intolerância ao outro, efeitos postos em jogo em inúmeros debates políticos na Câmara Federal, entrevistas de parlamentares, depoimentos de políticos não eleitos e seus desdobramentos nas mídias e nas redes sociais.

Esses sentidos reclamam interpretação, dado o modo como se constituíram e circularam. Postagens foram produzidas e passaram a povoar as redes sociais com dizeres que pedem a saída de Michel Temer do poder por meio de enunciados como "Fora Temer", "Rala Temer" após sua chegada ao governo por meio do processo de impeachment.

Vários foram e são os dizeres que entraram em disputa no processo de destituição no Brasil de Dilma Rousseff de seu posto de Presidenta da República legitimamente eleita por meio de 54,5 milhões de votos:

um processo que não se fez sem o poder de uma mídia dominante e dominadora, impedindo e apagando a circulação de outros dizeres, como cientistas sociais, historiadores, jornalistas, entre outros intelectuais, já vêm denunciando nacional e internacionalmente. Ao lado da mídia hegemônica e corporativa com seu martelo de repetição diário a apoiar tal processo, outra regularidade pôde ser observada: a ação (e omissão) do judiciário, seja pela publicização pessoal de um juiz à frente a Operação Lava Jato, que engendrou ações bastante espetaculares a respeito de denúncias de corrupção de agentes dos governos Lula e Dilma, seja pela forma como o Supremo Tribunal Federal silenciou-se diante da inconsistência de provas contra a presidenta. (MEDEIROS; SOUSA, s.d., s.p.)

As postagens que aqui analisaremos inscrevem efeitos de resistência, pela via do humor, após a entrada de Temer como presidente, fazendo estremecer o modo como tal ordem do político deslizou para situações cotidianas e fizeram com que os brasileiros começassem a produzir dizeres para fazerem frente ao discurso hegemônico produzido pela mídia e em circulação a respeito do presidente Michel Temer. Cidadãos indignados com a situação política brasileira põem suas vozes em circulação nas redes sociais e resistem, pela via do humor, aos sentidos que a mídia tradicional, muitas vezes, tenta empurrar-lhes.

Para a compreensão desse discurso, pela via do humor, que emerge nas postagens, é necessário considerarmos mais uma vez suas condições de produção. Como condições

\footnotetext{
${ }^{5}$ Para a Análise de Discurso, as condições de produção referem-se à situação e aos sujeitos. Em relação ao sujeito, na $\mathrm{AD}$, não é considerado o sujeito empírico, mas sim a posição sujeito projetada no discurso, estando relacionada aos lugares que os sujeitos aí ocupam. Já em relação à situação, essa pode ser pensada em sentido estrito e em sentido amplo: "Em sentido estrito ela compreende as circunstâncias da enunciação, o aqui e o agora do dizer. No sentido lato, a situação compreende o contexto sócio-histórico-ideológico" (ORLANDI, 2002, p. 15).
} 
de produção dessas postagens, temos: Brasil. Primeiras horas do dia 25 de dezembro de 2016. Momento de festas natalinas. Em circulação na mídia televisiva, o pronunciamento do presidente Michel Temer cumprimentando e desejando a todos os brasileiros um Feliz $\mathrm{Natal}^{6}$. Nas redes sociais, eclodem gritos de "Rala Temer":

\title{
Vi agora 0
} pronunciamento

(mentiroso, covarde) de @MichelTemer! Migo, pfv, renuncia e vamos antecipar as eleições! \#RalaTemer

\author{
$12: 09 \mathrm{AM} \cdot 25 \mathrm{dez} 16$
}

Figura 2: \#RalaTemer. Fonte:

https://www.facebook.com/alutaonline/photos/a.270991476413270.1073741827.270986239747127/7048571696 93363/?type=3\&theater.

\footnotetext{
${ }^{6}$ Trecho do pronunciamento de Michel Temer, a partir do qual as diversas postagens se formularão: "Boa noite! Nesta noite de Natal, dirijo-me a você e a todo povo brasileiro para transmitir mensagem de renovada esperança. $\mathrm{O}$ ano que está terminando trouxe imensos desafios. Assumi definitivamente a Presidência da República há pouco mais de cem dias. Tenho trabalhado dia e noite para fazer as reformas necessárias para que o país saia dessa crise e volte a crescer. O Brasil tem pressa. E eu também. Nesses poucos meses do nosso governo, muito já foi feito. Com os esforços que fizemos, a inflação caiu e voltou a ficar dentro da meta, o que vai colocar um freio na carestia que você sente no supermercado. Aprovamos a lei que bota ordem nos gastos públicos pelos próximos 20 anos. E a lei que moraliza e dá transparência à administração das estatais. Estamos começando a reforma da Previdência, para que sua sagrada aposentadoria esteja garantida agora e no futuro. Aprovamos, na Câmara, a reforma do Ensino Médio, que estava parada havia anos. Ampliamos em mais de 8 bilhões de reais o orçamento da saúde, área para qual não pouparei recursos. Mudamos a Constituição para mudar o Brasil. [...] Peço a você que acredite no Brasil. Desejo um Feliz Natal. Que seu gesto de amizade e de fraternidade nesta noite se estenda por todo o Ano Novo. Vamos juntos reconstruir o nosso país. Muito obrigado a todos. Boa noite, Brasil!". Disponível em http://www2.planalto.gov.br/acompanhe-planalto/discursos/discursos-do-presidente-darepublica/pronunciamento-de-natal-do-presidente-da-republica-michel-temer-1.
} 


\section{Fabianna Pontes \\ @FabiannaPontes \\ \#RalaTemer para o ano \\ ser bom.Apesar de já ter \\ prejudicado os pobre.A \\ verdade doi mas tem que \\ ser dita}

\section{$1: 13 \mathrm{AM} \cdot 25 \mathrm{dez} 16$}

Figura 3: \#RalaTemer. Fonte:

https://www.facebook.com/alutaonline/photos/a.270991476413270.1073741827.270986239747127/7048591730

26496/?type=3\&theater.

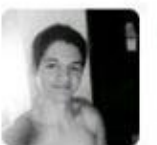

\section{Wesley David}

@wesley_david97

\section{Primeiramente \\ \#RalaTemer \\ Segundamente também \\ Desse governo golpista \\ Não reconheço ninguém}

\section{$1: 24 \mathrm{AM} \cdot 25 \mathrm{dez} 16$}

Figura 4: \#RalaTemer. Fonte:

https://www.facebook.com/alutaonline/photos/a.270991476413270.1073741827.270986239747127/7048592330 26490/?type=3\&theater.

Grito de rejeição e de deposição materializado na interjeição "Rala", grito que escreve a insubmissão e aponta para a insatisfação de uma parcela da população brasileira ao governo Michel Temer. Nos dizeres de Medeiros e Sousa (s.d.), "Ganhamos o grito de indignação que significa se recusar ao jogo do cinismo e significa que cada um de nós o fará a seu modo, ganhamos o grito que se manifesta em/por todos os poros da vida cotidiana e que faz reacender as maneiras que há de gritar".

Em circulação na rede social, o discurso da resistência sendo tecido por cidadãos comuns, sujeitos que navegam e usam do ciberespaço para refletirem sobre a política 
brasileira, nada de situações idealizadas, "tingidas de heroísmo" (ORLANDI, 2002), mas o cotidiano que afeta o brasileiro todos os dias. Na rede, a resistência se instaura como:

A possibilidade de, ao dizer outras palavras no lugar daquelas prováveis ou previsíveis, deslocar sentidos já esperados. É ressignificar sentidos e rituais enunciativos, deslocando processos interpretativos já inscritos historicamente, já institucionalizados. São deslocamentos que podem se dar de modo inesperado [...]. (SOARES et.al., 2015, p. 10)

E, nas postagens da página $A$ Luta, os deslocamentos se dão pela via do humor, inscrevendo outras significações tanto para Michel Temer como para a festa natalina. $\mathrm{O}$ humor funciona aqui como efeito de denúncia, de rebeldia frente ao governo (i)legítimo:

\section{(C) Mel de Xavasca @aguilover não é o pior do Natal.}

\section{2:19 AM · $25 \operatorname{dez} 16$}

Figura 5: \#RalaTemer. Fonte:

https://www.facebook.com/alutaonline/photos/a.270991476413270.10737411827.270986239747127/7048569763 60049/?type=3\&theater.

\section{Angelo Gabriel}

@TakiGabu

\section{Quem deveria ficar de fora} nessa ceia?

( ) Uva passa

( ) Fruta cristalizada

(X) Temer

\section{\#RalaTemer}

10:08 PM $\cdot 24$ dez 16

Figura 6: \#RalaTemer. Fonte:

https://www.facebook.com/alutaonline/photos/a.270991476413270.10737411827.2709862397477127/7048558963 60157/?type=3\&theater. 


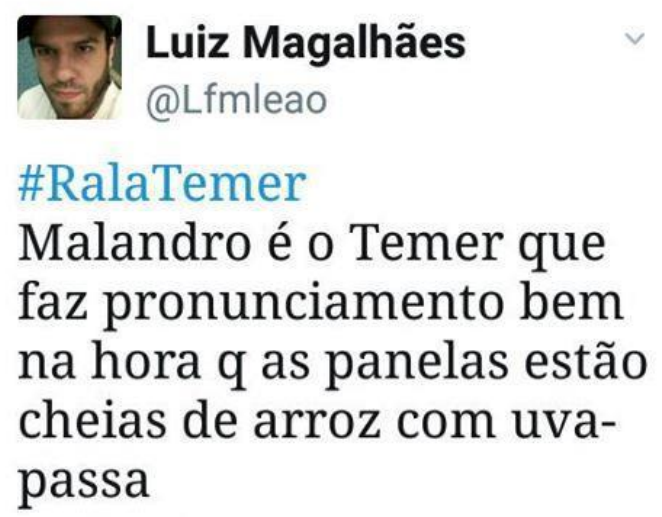

\section{8:36 PM $\cdot 24$ dez 16}

Figura 7: \#RalaTemer. Fonte: https://www.facebook.com/alutaonline/photos/a.270991476413270.1073741827.2709862397477127/7048559530 26818/?type=3\&theater.

Nas postagens acima, o jogo humorístico se faz com o deslocamento dos sentidos de algumas comidas natalinas, estando já estabilizados nessa época do ano os chistes com essas comidas típicas, e a comparação com Michel Temer A uva passa e as frutas cristalizadas têm ligação com os tempos da Roma Antiga e com o solstício de inverno, quando eram dadas de presente. Para os romanos, cada tipo de fruta seca tinha um significado e fazia parte de um costume dessa civilização antiga que prometia a ausência de fome, pobreza e ainda protegia contra os excessos da bebida ${ }^{7}$. Hoje, esse sentido esvaziou-se e essas frutas abrilhantam, nos chistes, tanto de quem gosta como de quem não gosta, a ceia de Natal. Ao jogar, pelo humor, deslocando o significante uva passa para Temer, os sujeitos vão indiciando seu posicionamento contrário ao governante, inscrevendo que o pior do Natal é o presidente Temer estar no poder e fazer uso de sua posição para aprovar propostas que afetam negativamente o povo brasileiro. Propostas estas que não passam por uma discussão com o cidadão brasileiro, mas lhes são impostas na forma de lei.

Mais uma vez, joga-se aqui com o significante panelas. Em uma retomada dos panelaços, indicia sua ausência nos pronunciamentos de Temer, brincando com o fato de as panelas, na época do Natal, em geral, em virtude, muitas vezes, de ações sociais, estarem cheias de comida ("arroz com uva passa"). Nessa postagem, constitui-se a Temer a imagem de um governante que sabe qual o melhor momento para agir sem ter sua aceitação colocada em confronto. Um presidente "malandro" que, em surdina, planeja o golpe a um governo que antes apoiava:

\footnotetext{
${ }^{7}$ Disponível em http://www.jornaljr.com.br/2016/12/23/uva-passa-na-comida/.
} 


\section{Geraldo Filho \\ @GeraldoSiFi30}

Na véspera de Natal vem

Belzebu, com fucinho todo

esticado de botox, falar q

tá se esforçando pra ferrar

ainda + com o Povo!

\#RalaTemer

12:58 AM $\cdot 25 \mathrm{dez} 16$

Figura 8: \#RalaTemer. Fonte:

https://www.facebook.com/alutaonline/photos/a.270991476413270.1073741827.270986239747127/7048593863

59808/?type=3\&theater.

Nessa postagem, o riso se instaura por meio da comparação de Michel Temer com Belzebu, considerado, pelo cristianismo moderno, como o príncipe dos demônios, sendo o quarto demônio mais poderoso do inferno, estando submisso somente a Lúcifer, Satã e Belfregor. O humor aqui se dá por meio da exaltação de algumas características físicas de Michel Temer ("fucinho todo esticado de botox"). Fazendo uso de um humor mais satírico, desumaniza-se o presidente e mostra-se seu lado mais diabólico, o lado que impõe longos anos de jornada de trabalho para a aposentadoria, congelamentos dos gastos públicos por 20 anos:

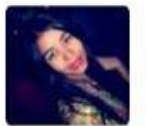

Fernanda Souza

@MsNandaSouza

\#RalaTemer ñ consegui

nem ir até a metade

desse pronunciamento do

Temer. " botar ordem nos

gastos pelos próximos 20

anos" vai se $\mathrm{f} \# \wedge \div \& ! ! !$

1:12 AM $\cdot 25 \mathrm{dez} 16$

Figura 9: \#RalaTemer. Fonte:

https://www.facebook.com/alutaonline/photos/a.270991476413270.1073741827.2709862397477127/7048592763

59819/?type=3\&theater. 


\title{
Isaac Nervoso
}

@lsaacNervoso

\section{Temer é benéfico para o Natal... por exemplo, se depender dele 0 Papai Noel nunca vai se aposentar.}

\section{\#RalaTemer}

\author{
$12: 58 \mathrm{AM} \cdot 25 \mathrm{dez} 16$ \\ Figura 10: \#RalaTemer. Fonte: \\ https://www.facebook.com/alutaonline/photos/a.270991476413270.1073741827.270986239747127/7048594930 \\ 26464/?type=3\&theater.
}

O uso da hashtag \#RalaTemer indica o posicionamento dos sujeitos-navegadores da rede social Facebook em relação ao governo Temer. Um posicionamento que o considera diabólico, temerário, pior coisa do Natal. Tecnicamente, a formulação de uma hashtag se dá pela junção de uma cerquilha (\#) que funciona como um hiperlink de assuntos indexados por mecanismos de busca, tais como o Google, na rede (DIAS, COELHO, 2014, p. 235). Seu uso permite que sujeitos-navegadores do ciberespaço cliquem nas hashtags ou as busquem nos mecanismos de busca para terem acesso a mensagens, fotos e publicações que participam da discussão de um tópico nas redes sociais. Discursivamente, as hashtags marcam um funcionamento que clama pela saída de Michel Temer do poder. Fazendo uso do humor nas redes sociais, os sujeitos, por fim, não se resignam, mas afirmam-se resistentes diante do cenário político brasileiro.

\section{Como efeito de fim...}

Neste trabalho, ancorados na Análise de Discurso, analisamos algumas postagens que circularam na página do Facebook A Luta que, fazendo uso do humor rebelde, diz acerca da situação política brasileira e sobre a impopularidade do presidente Michel Temer em virtude de algumas propostas para se conterem os gastos públicos (congelamento de investimento na educação por 20 anos, aposentadoria após 49 anos de contribuição, entre outras reformas). Como mostramos nas análises, a partir de um pronunciamento do presidente Michel Temer no Natal de 2016, diversas postagens circularão no ciberespaço para produzirem outra significação sobre a política brasileira e o presidente do Brasil. Com o "Rala Temer", os sujeitos, ao usarem a rede social Facebook, gritam e riem, um riso que não reconcilia, na noite natalina, a (i)legitimidade de um governo que chega ao poder por meio do impeachment de uma Presidenta legitimamente eleita pelo povo brasileiro. 


\section{Referências}

DIAS, C.; COELHO, A. V de Vinagre: a produção de imagens humorísticas sobre as manifestações brasileiras de 2013 nas redes sociais. Em: PATTI, A.R. et al. Textecendo discursos na contemporaneidade. São Carlos: Pedro \& João Editores, 2014.

FREUD, S. [1927]. O humor. Em: Edição standard brasileira das obras psicológicas completas. Rio de Janeiro: Imago, 1980 [v. XXI].

LIPOVETSKY, G. A era do vazio. Ensaio sobre o individualismo contemporâneo. Lisboa: Relógio D’Agua, 1989.

LEANDRO-FERREIRA, M.C. Resistir, resistir, resistir... Primado prático discursivo. Em: SOARES, A.F. et al. (Org.). Discurso, Resistência e.... Cascavel: Ed. Unioeste, 2015. p. 159-167.

MEDEIROS, V.; SOUSA, L.M.A e. Efeitos de um Fora: o grito desdobrado na ordem da vida. (no prelo).

MORAIS, M.B.L. Humor e psicanálise. Estudos de Psicanálise, Salvador, n. 31, 113 123, 2008.

Com as unhas cravadas no mal-estar. Entrevista a COIHU on-line. Disp. em http://www.ihuonline.unisinos.br/index.php?option=com_content\&view=article\&id=39 $\underline{60 \text { secao }=367 \& \text { limitstart }=1}$. Acesso em 19 jan. 2017.

ORLANDI, E. Análise de Discurso: princípios e procedimentos. Campinas: Pontes, 2002.

PÊCHEUX, M. [1975]. Semântica e discurso: uma crítica à afirmação do óbvio. Campinas: Editora da Unicamp, 2009.

Artigo recebido em: maio de 2017.

Aprovado e revisado em: setembro de 2017.

Publicado em: novembro de 2017.

Para citar este texto:

GARCIA, Dantielli Assumpção; FLORES, Giovanna G. Benedetto. O humor nas redes sociais: a sátira sobre a política em A Luta. Entremeios [Revista de Estudos do Discurso, on-line, www.entremeios.inf.br], Seção Temática [Linguagem e Tecnologia], Programa de Pós-Graduação em Ciências da Linguagem (PPGCL), Universidade do Vale do Sapucaí (UNIVÁS), Pouso Alegre (MG), vol. 15, p. 199-211, jul. - dez. 2017.

DOI: http://dx.doi.org/10.20337/ISSN2179-3514revistaENTREMEIOSvol15pagina199a211 